\title{
Factors Impacting and Restricting Success of Organisational Changes
}

\author{
Renata Korsakienè ${ }^{1}$, Rūta Juodeikè ${ }^{2}$, Monika Bužavaitè ${ }^{3}$ \\ ${ }^{1,2}$ Department of Enterprise Economics and Management, Vilnius Gediminas Technical University, \\ Vilnius, Lithuania \\ ${ }^{3}$ Valuetech s.r.l., Torino, Italy \\ E-mails: 'renata.korsakiene@vgtu.lt (correspondingauthor); ${ }^{2}$ ruta.juodeike@stud.vgtu.lt; \\ ${ }^{3}$ monikabuzavaite@gmail.com
}

Received 22 Fabruary 2017; accepted 07 April 2017

\begin{abstract}
Social, economic and technological changes constantly change business landscape and raise an array of challenges to organisations. Organizations have to adapt to the environmental changes and maintain competitiveness and flexibility. Thus, changes aim to transform current state of organisations, to increase productivity and competitive advantage in the market. On the other hand, a number of investigations confirm that majority of organisational changes fail and do not produce an expected performance. Scientific literature suggests various management methods and links these methods to the desirable outcomes. Considering the fact that organisations are unique systems, some change management models do not capture such aspects as exceptional experience, culture, intuition of managers, etc. These issues lead to the restricted application of majority of models or methods. The opinions of scholars about definition and measurement of success diverge. The paper aims to investigate the factors impacting and restricting organisational changes. Particular emphasis is put on the success as the desirable outcome of all initiatives. The investigation is based on analysis and synthesis of scientific literature. A case of service providing company is presented. The paper integrates the main researches in the field and provides insights and recommendations into future investigations.
\end{abstract}

Keywords: organisational changes, management of changes, process of changes, success of organisational changes, restricting factors, impacting factors.

JEL Classification: M10, M14, M19.

Conference topic: Modern Business Management Problems and Perspectives.

\section{Introduction}

Social, economic and technological changes constantly change business landscape and raise an array of challenges to organisations. The pressure, originating from the market forces, encourage constantly improve performance and maintain flexibility. Thus, success of organisations stems from their ability to exploit opportunities and implement changes. The agents of changes are encouraged constantly observe internal and external context and take immediate actions. These tendencies let us explain that changes have become a norm in current organisations and are essential for the long-term success. On the other hand, a number of investigations confirm that majority of organisational changes fail and do not produce an expected performance. Thus, the studies report small success rate $(<30 \%)$ of all change programs (Al-Haddad, Kotnour 2015). Scientific literature suggests various management methods and links these methods to the desirable outcomes. Considering the fact that organisations are unique systems, some change management models do not capture such aspects as exceptional experience, culture, intuition of managers, etc. Thus, the low success rate encourages the scholars to investigate factors, leading to the higher success probability.

The observations of scientific literature lead to the fact that majority of investigations, focused on change management issues, were performed in the developed market context. On the other hand, various studies emphasise different concepts, types of changes, change aspects and distinguish different driving forces (Al-Haddad, Kotnour 2015; Brown 2014; Walker et al. 2007). Meanwhile, the number of studies performed in emerging markets' context is limited. These studies emphasise some theoretical and practical issues of change management (Korsakienè 2006), investigated change management in public sector (Iljins et al. 2014), etc. The paper aims to investigate the factors impacting and restricting organisational changes. Particular emphasis is put on the success as the desirable outcome of all initiatives. The investigation is based on analysis and synthesis of scientific literature. A case study of service providing company is presented.

(C) 2017 R. Korsakienė, R. Juodeikè, M. Bužavaitè. Published by VGTU Press. This is an open-access article distributed under the terms of the Creative Commons Attribution (CC BY 4.0) License, which permits unrestricted use, distribution, and reproduction in any medium, provided the original author and source are credited. 


\section{The concept and types of organisational changes}

The changes of business context shape new business landscape for all organisations. The interactions of various stakeholders such as competitors, customers, employees, suppliers, shareholders, governmental organisations and society have led to the need implement organisational changes. The demand for organisational changes is shaped by new competitors' strategies, scope of competition, changing customers' needs, new regulations, evolving norms and values of society, etc. Hence, the capabilities of organisations to implement changes have become the main precondition for long-term survival and growth (Brown 2014). On the other hand, organisational changes have become the undoubted challenges for both profit-seeking and non-profit organisations. The explanation lies in the fact that the outcomes of changes are difficult to predict and the progress is difficult to observe (Carnall 2007). Therefore, the studies confirm that majority of initiatives fail to produce the desirable change outcomes (Hamlin 2016; Burnes 2009; Burke et al. 2009; Al-Haddad, Kotnour 2015).

Scientific literature, investigating organisational changes, provides many concepts and emphasises different aspects of changes. A number of competing definitions lead to the conclusion that scholars have not agreed upon the common definition. For instance, Kotter (1995) defined organisational changes as the process, devoted to the understanding and acceptance of foreseen changes. The attitude, that coinciding values and norms of both organisation and individuals support organisational changes, has been prevailing. A number of scholars grounded their investigations on the Lewin's model, which defined the changes as the three-stage process comprised of unfreezing, changing and freezing steps. Meanwhile, other scholars defined organisational changes as a complex and dialectical process, where driving force develops and is impacted by the process itself, and "where old and new intertwine, cumulatively building an innovative dynamic" (Jansson 2013). Some scientists interpret organisational changes as a constant state of organisation, which comprise all activities, performance and routines (Burnes 2009). Hence, the changes as the process and as the particular state are interrelated with the strategy of organisation and vice versa. This approach coincides with the opinion, stating that organisational changes are any intentions, affecting strategic position of the organisation visà-vis its competitors (Smith 2002). The changes are perceived as a multifaceted phenomenon, which depends on the content of changes, external and internal context (Soparnot 2011). The effectiveness of changes depends on the ability of organisation to make the decisions (the aspect of content), respond to the development of external environment (external environment aspect) and/or the development of internal environment (internal environment aspect), aiming to assure successful implementation of changes.

While some scholars were concerned with the concept per se, others distinguished the following levels of changes: individual level, department or group level and overall organisational level. At the individual level, the changes occur when the employee obtains new capabilities, develops new work methods and experiences mentoring, training and development. At the department or group level, the changes occur when the new methods of communication are developed, new objectives and tasks are defined, new conflict management methods are introduced. At the organisational level, the changes appear when new strategies, processes, vision and management systems are developed. In addition, the changes might appear at the inter-organisational level (i.e. by implementing mergers and acquisitions) and are common among business and non-profit organisations, different cities or even the states (Anderson 2010; Burke et al. 2009). The attitudes of scholars towards organisational changes are summarised in Table 1.

Table 1. The attitudes towards organisational changes (Source: developed by authors)

\begin{tabular}{|c|c|c|}
\hline Prevailing attitude & Authors & Concept of organisational changes \\
\hline \multirow[t]{7}{*}{$\begin{array}{l}\text { Organisational changes as a } \\
\text { process }\end{array}$} & Kotter (1995) & $\begin{array}{l}\text { Organisational changes are seen as the process, focused on } \\
\text { the understanding and acceptance of changes. }\end{array}$ \\
\hline & Carnall (2007) & \multirow{5}{*}{$\begin{array}{l}\text { Organisational changes are seen as the three-stage process } \\
\text { comprised of unfreezing (dismantling of existing practices), } \\
\text { changing (implementation of changes) and refreezing (new } \\
\text { practices established and comfort level restored) fazes. }\end{array}$} \\
\hline & Walker et al. (2007) & \\
\hline & Smith (2011) & \\
\hline & Ronnenberg et al. (2011) & \\
\hline & Hurn (2012) & \\
\hline & Jansson (2013) & $\begin{array}{l}\text { Organisational changes are seen as a complex and dialectical } \\
\text { process, where driving force develops and is impacted by } \\
\text { the process itself, and "where old and new intertwine, cumu- } \\
\text { latively building an innovative dynamic". }\end{array}$ \\
\hline $\begin{array}{l}\text { Organisational changes as a } \\
\text { constant state }\end{array}$ & Burnes (2009) & $\begin{array}{l}\text { Organisational changes are defined as a constant state of or- } \\
\text { ganisation and comprise all activities, performance and rou- } \\
\text { tines. }\end{array}$ \\
\hline $\begin{array}{l}\text { Organisational changes as a } \\
\text { multifaceted phenomenon }\end{array}$ & Soparnot (2011) & $\begin{array}{l}\text { The changes are seen as the multifaceted phenomenon, } \\
\text { which depends on the content of changes, external and inter- } \\
\text { nal context. }\end{array}$ \\
\hline
\end{tabular}


Notably, a number of approaches towards organisational changes have led to the different opinions about types of changes. Early studies on changes distinguished alpha, beta and gamma changes (Golembiewski et al. 1976). Alpha changes appear in objective and in comparatively stable or lightly changing circumstances. This type of changes is seen as the ordinary changes. Meanwhile, beta changes are observed when the assessment of perception scale is changing (e.g. individual start differently perceive and interpret norms, assessment scales etc.). Gamma changes occur when individual's perceptions about evaluated object radically changes.

According to Al-Haddad and Kotnour (2015), types of changes are distinguished into two categories: scale of change and duration of change. Thus, changes can be small vs large and short vs long term. Meanwhile, aiming to group changes, Anderson (2010) selected the following criteria: planning, significance and continuity. The selected approach has led to planned or unplanned changes. A number of various factors such as the impact of environmental factors, the need to respond to customers' needs, the need to adopt strategic changes influence the implementation of planned changes. Meanwhile, unplanned changes are implemented aiming to respond to the crisis and sudden threats. Considering the significance of changes, first and second-degree changes have been distinguished. Notably, first degree changes are comprised of separate changes or corrections, focused on already established and prevailing operation systems, methods and practices. Second-degree changes are defined as transformations and reflect more complex changes, focused on the implementation of new operation systems, methods and practices. Continuity of changes let us distinguish separate or episodic and permanent changes. Episodic changes appear in different periods of existence, they are explicit and less frequent. Notably, permanent changes reflect the state of organisation when changes are constantly undertaken or appear (Anderson 2010).

Some scholars focused their efforts on planned and unplanned changes (Burnes 2009). Considering frequency and scope, planned changes can be divided into the following types: incremental, punctuated equilibrium and continuous change. Thus, the advanced changes, i.e. the process when separate parts of organisation gradually and individually solve one issue and aim one target, are emphasized. Meanwhile, punctuated equilibrium occurs when external and internal environment are changing. Notably, continuous changes are seen as the constant change of work processes and social practices. This state of organisation is impacted by instability and readiness to adapt to unforeseen daily circumstances.

Brown (2014) relied on so-called Lawrence and Leavitt models and suggested four types of changes: structural, technological, behavioural and integrated. According to scholar, technological changes are related to measurable changes, implemented in daily operations. Meanwhile, behavioural changes are related to the changes implemented in established relations. The purpose of structural changes is to optimise the activity of organisation by carefully defining organisational structure. Brown (2014) observes that current organisations have to accept prevailing interrelationships of various elements and the fact, that implemented changes in one sub-system of organisation influence other organisational elements. Hence, the integration of all categories of changes is required in one organisation. Carnall (2007) classifies changes considering clinical, linear, systemic and emerging approaches. Table 2 presents typologies of organisational changes.

Table 2. Typologies of organisational changes (Source: developed by authors)

\begin{tabular}{|c|c|c|}
\hline Author & Types of changes & Description of changes \\
\hline \multirow[t]{2}{*}{$\begin{array}{l}\text { Al-Haddad, Kotnour } \\
\text { (2015) }\end{array}$} & Scope & $\begin{array}{l}\text { - Small } \\
\text { - Large }\end{array}$ \\
\hline & Duration & $\begin{array}{l}\text { - Short-term } \\
\text { - Long-term }\end{array}$ \\
\hline \multirow[t]{3}{*}{ Anderson (2010) } & Planning & $\begin{array}{l}\text { - Planned } \\
\text { - Unplanned }\end{array}$ \\
\hline & Significance & $\begin{array}{l}\text { - First degree } \\
\text { - Second degree }\end{array}$ \\
\hline & Continuity & $\begin{array}{l}\text { - Episodic } \\
\text { - Permanent } \\
\end{array}$ \\
\hline \multirow[t]{4}{*}{ Brown (2014) } & Structural & Implemented in organisational structure \\
\hline & Technological & Implemented in daily operations \\
\hline & Behavioural & Implemented in established relationships \\
\hline & Integrated & $\begin{array}{l}\text { Implemented in all three dimensions (structure, daily operations and } \\
\text { established relationships) }\end{array}$ \\
\hline \multirow[t]{2}{*}{ Burnes (2009) } & Planned & $\begin{array}{l}\text { - Incremental } \\
\text { - Punctuated equilibrium } \\
\text { - Continuous change }\end{array}$ \\
\hline & Unplanned & Sudden and unpredicted \\
\hline \multirow{3}{*}{$\begin{array}{l}\text { Golembiewski et al. } \\
\text { (1976) }\end{array}$} & Alpha & Appear in comparatively stable circumstances \\
\hline & Beta & Appear when assessment of perception scale is changing \\
\hline & Gamma & Occur when the perception about evaluated object radically changes \\
\hline
\end{tabular}


The review of scientific literature has led to the conclusion that scholars emphasize different aspects of organisational changes and thus, interpret the concept differently. While some scholars assume organisational changes as a certain process, others conclude that in current circumstances the changes are a constant state of organisation. Finally, a stream of scholars emphasises the need to interpret changes as a multifaceted phenomenon. Notably, different approaches to changes influence different classification types of changes. In line with the notion of some studies, we assume that organisations are unique systems and thus, the changes are implemented constantly and as the separate projects, are implemented immediately or are continuous. Hence, the scale of changes ranges from the corrections of local departments to a large-scale transformation of organisation (Smith 2011; Kogetsidis 2012).

\section{Factors restricting and affecting success of changes}

The authors of scientific literature agree that changes have become a norm in current organisations. However, the change management is a complicated and multifaceted process (Burnes 2009). A high percentage of unsuccessful changes encourage the observations of factors increasing or decreasing the probability of success (Al-Haddad, Kotnour 2015).

The organisations are comprised of acting individuals and thus change leaders have to cope with the resistance to changes. The resistance to changes is the factor, limiting the success of changes. The literature defines the resistance to changes as the adverse behaviour and attitudes of organisational members in response to the efforts of change leaders. Some scholars assert that resistance to changes is interrelated to the attempts to maintain status quo (Jansson 2013). Meanwhile, Carnall (2007) assumes that the resistance to changes is the resistance to the uncertainty. Hence, the resistance occurs due to inappropriate readiness of organisation and management. The implied risk and uncertainty of change performance influence the resistance of individuals. These aspects are general to all changes and thus the resistance can occur at both levels: individual and overall group (Kim 2015). According to Johannsdottir et al. (2015), the resistance to changes fall into four categories: openly expressive resistance, concealed resistance, active and passive resistance. Openly expressive and active resistance refer to the behaviour when the individuals openly present counterarguments, argue and sabotage change efforts. Meanwhile, concealed and passive resistance refer to the behaviour when the individuals withdraw, avoid taking actions, delay to take initiative. The roots of resistance lie in organisational culture and thus, require managers to understand what factors assure the higher probability of change success.

Walker et al. (2007) emphasized the following issues, affecting success of organisational changes: content, context and process of changes. The implemented changes, which are specific to each organisation, i.e. are episodic or permanent, sudden and unpredictable or carefully planned, defines the content of changes. Meanwhile, process issues include the actions of change agents taken in the implementation of changes. Context of process refer to the external and internal factors, affecting organisation. The organisations have limited capacity to control external forces and have to change, aiming to react appropriately. The factors of internal context include the level of proficiency, the approach of management towards the changes, technical knowledge, availability and accessibility of resources. The scholars asserted that investigations of organisational changes have to consider the difference between the change leaders and objectives of changes. In addition, the obtained experience in the implementation of changes shapes internal context. For instance, lower confidence of change leaders, unsuccessful change efforts in the past influence cynical approach, which negatively affects success. Walker et al. (2007) distinguished the difference of individuals and their personal traits and attitudes, which have strong influence to the attitudes and behaviours prevailing in organisation. These differences of individuals influence the response to the changes and commitment to the changes. Thus, the scholars investigated the impact of integrated factors and suggested the model, grounded on the more macro-level factors (content, process and context) and on the micro-level factors (e.g. individual differences). Notably, all participants of the study were involved in the same change efforts and experienced similar change content. The scholars selected the following factors affecting changes: tolerance for ambiguity, cynicism of employees and change beliefs. Cynicism of employees was interpreted as the "loss of faith in change agents" and change beliefs were the important factor, influencing employees' commitment. These preconditions have led to the development of research hypotheses. Firstly, tolerance ambiguity negatively influences change beliefs. Secondly, tolerance ambiguity negatively influences employees' cynicism. Thirdly, employees' cynicism negatively influences change beliefs. Fourthly, cynicism of employees negatively influences employees' commitment to change. Finally, change beliefs negatively influence employees' commitment to change. The study investigated employees from two production lines of newly established company, operating after spin-off efforts of the production company. According to Walker et al. (2007), the study revealed that change content, context, process and differences of individuals influence success of organisational changes. The authors assessed and grounded integrated model and thus expanded extant knowledge on response of employees towards changes. The study has led to the development of theoretical guidelines contributing to the implementation of change efforts.

Some scholars adopted the approach that change management involves overall business and employees as the main actors of changes (Brown 2014). Thus, the main factors influencing success of changes are: 1) change representatives (advocates), initiating and supporting changes, 2) change degree, ranging from nonessential to extreme; 3) duration of changes; 4) organisational culture, triggering the growth of resistance to change; 5) assessment of changes, which leads to the timely corrections and thus assures successful implementation of changes. Meanwhile Burnes (2009) 
distinguished factors, which depend on external context, focus of management, leadership skills and other circumstances, which foster and restrict implementation of changes. The scholar distinguished five factors, affecting success of changes: organisational structure, organisational culture, and organisational development, behaviour of managers, power and politics. Organisational structure is comprised of formal and informal elements, which significantly influence changes. Organisational structure defines distribution of power in organisation, defines relationships among the members and direct organisational activities towards the objectives. When organisation operates in fast changing environment, flexible and adaptive structure is essential in comparison to the hierarchical and bureaucratic structure. Organisational culture, tolerating changes, leads to the acceptance and support of changes. Meanwhile, inflexible organisational culture is characterised by the strong resistance to changes and thus implementation of changes becomes more complicated. Organisational development significantly influences the readiness of all members to cope with changes. The individuals are encouraged independently define areas of organisation which require changes. The desire of organisation's members to change originates from the unsatisfied methods of operations, systems, procedures and perceptions that changes are inevitable. Meanwhile, the regulations to change particular work areas provoke the resistance and desire to retain old work practices. The behaviour of managers defines the behaviour of organisation's members. When managers act as the developers and supporters of organisation's members, overcome hierarchical, functional and organisational limits, develop the feeling of solidarity, and enable members of organisation to change, the probability of success increases significantly. Thus, the support of powerful stakeholders becomes crucial is the first stages of change project.

Scientific investigations emphasised the readiness for change as one of the most important success factors. The readiness for change is defined as the efforts of organisation to initiate and implement changes (Imran et al. 2016). In addition, the readiness for change is seen as a commitment of organisation's members to changes and self-efficacy in implementation of changes (Al-Haddad, Kontour 2015). The readiness of organisation has become an integrated part of planning stage, when the initiators of changes have to deal with the following issues: available resources necessary to start the changes and level of organisation, which require implementation of changes (Imran et al. 2016). The studies disclosed the positive correlation between the readiness for changes and successful management. Hence, the scholars assert that managers and employees of organisation can experience losses due to the lack of communication, appropriate management, supportive instruments and necessary resources (Edmonds 2011). Organisational readiness comprises the efforts of change agents to influence beliefs, intentions and behaviour of individuals and powerful stakeholders (Walker et al. 2007). Thus, organisational readiness let to predict possible reactions of organisational members, assure timely communication, prepare individuals to planned changes, shape change management strategy and forecast performance.

Meanwhile, communication is another factor, affecting success of changes. According to scholars, communication eliminates the barriers between change agents and individuals, affected by the changes (Sikdar, Payyazhi 2014). In addition, in the context of changes communication diminishes the sense of uncertainty and positively or negatively influences the response of individuals towards changes (Appelbaum et al. 2012). The aim of communication is to convince organisational members and other stakeholders about the necessity and benefits of changes. On the contrary, a lack of communication creates the threats and the senses of uncertainty, alienation and anxiety. Thus, due to the experienced stress, the employees' absenteeism and the turnover increase, the productivity and involvement diminish (Rehman 2011). Change leaders have to rely on various communication methods and to take into consideration the content of information. Thus, the leaders are required to present formal information, provide feedback, develop the readiness of organisation, the sense of urgency, motivate organisational members, manage conflicts, negotiate, etc. (Gilley et al. 2009). The observations of scientific literature let us conclude that the resistance to changes can be diminished through various means. These means include the readiness of organisation, the development of vision, efficient communication and education of individuals, collaboration and demonstration of power (Witteloostuijn, Zeyse 2013). Thus, contextual factors, content of changes, process of changes and individual characteristics have to be taken into consideration. On the other hand, the appropriate assessment system of changes leads to the higher probability of success. Thus, some aspects of measurement approaches require deeper understanding.

\section{Success of organisational changes}

A number of prevailing issues let us assume that small percentage of successfully implemented changes, which is low according to the scientific literature, reveal inappropriate assessment of performance. The assumption discloses the fact that leaders are careless about change management and other activities such as project management or risk management and thus delegate important change management tasks to other members of organisation (Arnold 2015). Thus, change leaders distance themselves from the challenge to implement strategic priorities and increase the probability of failure. According to Arnold (2015), the progress observation in the implementation of changes is the most important task, assigned to the leaders of organisation. The appropriate progress observation lead to the higher opportunity to anticipate and act immediately when the direction of progress changes.

The organisation, implementing changes, has to develop the assessment system (performance indicators) and align this system with the main objectives of organisation, the objectives of changes and the daily operations. These 
indicators enable change leaders to obtain and analyse information about implementation of changes. Notably, in the development of assessment system selected indicators have to reflect the factors, affecting higher efficiency in all levels of organisation and thus, include business processes, financial activities, customer satisfaction, growth and development of overall organisation. Al-Haddad and Kotnour (2015) assert that the success is defined by the completion of change project within predetermined objectives (e.g. budget, time, etc.) and customer satisfaction. Smith (2002) suggested the following success categories: ratings of overall success, project management, operations performance, management behaviour, customer, enterprise performance and owner (Table 3).

Table 3. Success categories and measures (Source: Smith 2002)

\begin{tabular}{ll}
\hline \multicolumn{1}{c}{ Category } & \multicolumn{1}{c}{ Measures } \\
\hline Ratings of overall success & Satisfaction of change, stakeholder expectations are met \\
Project management & Project completed on time, on budget, with promised features and etc. \\
Operations performance & Cost reduction, cycle time reduction, productivity gain, product/service \\
Management behaviour & Control, speed of decision-making, reduced layers of bureaucracy \\
Customer & Customer satisfaction, sales \\
Enterprise performance & Earnings, ROE, revenue growth/loss, operating profit, market share, cash \\
Owner & Shareholder value \\
\hline
\end{tabular}

Lee and Ahn (2008) investigated changes in the context of processes and concluded that successful changes have to rely on the efficient formulation and implementation of assessment criteria. The scholars observed that organisations are tended reorganise business processes, but poorly assess the impact of changes. The managers neglect the fact that changes can be less beneficial, harmful and costly in comparison to the expected performance. Grounded on the assumption, that value of changes has to be assessed, the authors suggested the assessment model of process improvement, enabling predict the performance of change initiatives. The main criteria of suggested model are cycle time, process bottleneck, cycle costs and resource utilisation. Cycle time in the assessment model refers to the duration of process and is a measure of process efficiency. Cycle time is comprised of process delay and processing time. Hence, the possibility to diminish cycle time (e.g. the faster product introduction to the market due to shorter time from order to delivery) is seen as the essence of process change. Meanwhile, process bottleneck occurs when each task in the process limit the output due to the available resources of organisation. Hence, the organisations, aiming to eliminate this phenomenon, have to change production plans or increase the capacity by hiring more employees, etc. Cycle costs include all direct and indirect costs, which are required to the process tasks. Notably, cycle costs and cycle time are interrelated together. Resource utilisation indicates to which extent resources are over and underutilised. Thus, resource utilisations let observe how much work is performed in relation to the capacity. According to Lee and Ahn (2008), the analysis of change objectives requires indicating variables of analysis. Some variables are disclosed through interviews with the members of organisation, by observing processes and by indicating the relationships between variables. The suggested model was applied in analysing a case of the company, producing pagers and cellular phones. The increasing competition among producers has led to the shortened life cycle of products. Hence, the company had to deal with the issue how to improve production and purchase processes. Aiming to perform all four analyses, the process and interrelated data have to be transformed into understandable and available to the implementation form of data. Thus, the analysis of 'what-if' is performed and the functioning of the transformed process in real circumstances is investigated. The study has led to the conclusion that the assessment of the process lead to the lower implementation costs, diminished resistance to change, faster implementation and understanding of the overall process.

While some aspects of changes can be evaluated quantitatively and can rely on financial and productivity ratios, other aspects can be evaluated qualitatively (e.g. customer satisfaction, satisfaction with change etc.). Hence, change leaders have to rely on some instruments such as "Six Sigma" and additional assessment means (e.g. Balanced scorecard), enabling to evaluate soft aspects of change progress (Burnes 2009). To conclude, the success of changes remains a multifaceted phenomenon and thus requires the managers to consider the size of organisation, the objectives and motives of changes and the types of changes. The development of assessment system let organisations to achieve defined objectives and to trace progress. Hence, the appropriate indicators of changes comprising both quantitative and qualitative ratios lead to the timely analysis, assessment and response. However, extant studies on change management do not answer to a number of questions. Hence, future investigations have to lead to the agreement how to define the success of organisational changes, how to assess the costs of resistance to the changes, how to assess the exceed expectations of implemented changes, how to trace the success in implementation of changes. In addition, the scholars have to agree on the following questions: 1) could we assume that the changes, which achieve the objectives, are successful per see; 2) could we attribute changes to unsuccessful or less successful when the objectives achieved, but at the expense of high costs? 


\section{Case study}

The investigation was carried out in the service providing company, operating in Lithuania. The company adopted Lean method and experienced a range of various changes. The adoption of Lean was triggered by the increased competition in the business and the demand of stakeholders to increase productivity of overall company. The change program was led by a group of individuals, responsible for the achieved objectives, the observation of progress, the training of employees and the selection of project managers. The project managers were assigned to each department of the company. The implementation of the project took three months and included several stages. In the preparation stage, the objective was to identify the scope of changes and the main stakeholders. In the identification of current state, the objective was to analyse current situation by observing performance indicators, processes, etc. The meetings with employees were organised and the expectations of employees were discussed. These meetings let to disclose the changes required in each part of organisation. In the development of future state, the objective was to define the desirable performance and the detail plan leading to the changes. In the implementation stage, the objective was to develop the more detail plan and to implement the plan. The project managers were assigned responsibility to organise the training courses and involve line managers and all employees into implementation of changes. Finally, the line manager and subordinates were able to assess the performance, to find the means leading to the development and to respond to the customer needs at the lowest costs. Thus, the continuous development stage was achieved.

The project was focused on the following areas: processes, development of skills and work organisation, operation management, attitude and behaviour. The processes of the company have to focus on the customers' needs and thus the employees have to know the exact time allocated to various tasks. The processes of the company have to be described. The skills and work organisation require to define the jobs in the company, to clarify the skills, to develop training plan and to predict substitutability in each process. Notably, work organisation refers to the clear functions of employees and the responsibilities of the departments. Meanwhile, operations management refers to the clear objectives of each department and the integration of these objectives into overall company's objectives. The departments are assigned performance indicators, which let to trace the progress. The attitude and behaviour refer to the employees' understanding of vision and values of the company. The culture based on the constant feedback is developed.

The pilot study included semi-structured interviews with the managers of the departments. The six managers agreed to participate in the interviews. Considering prevailing scientific practice, the interview took about fifty minutes and was recorded. Later on, the obtained data were transcribed and analysed. The interviewees were asked to discuss the success ratios and the success impacting factors.

The answers to the questions about the success rations let us reveal that the diminished costs and increased sales are seen as the main outcomes of the change programme. Four interviewees commented that "due to the implemented programme the costs decreased by $25 \%$ in our department". Meanwhile, two interviewees indicated that the number of mistakes in various operations has decreased. Finally, the number of employees slightly decreased or did not decline. To conclude, the performance success assumed by the managers coincide with the success measures suggested by Smith (2002). The answers to the questions about the success factors have led to a number of various explanations. For instance, majority of interviewees disclosed that the competence of change managers plays a crucial role in the change process. In addition, four interviewees indicated that "the support of top managers was the driving force to change". Thus, the obtained data coincide with the opinions expressed in the scientific literature (Burness 2009; Brown 2014). Three out of six interviewees mentioned the following factors: motivation, employees' involvement and constant observation of progress. Meanwhile, one of six interviewees indicated communication and accumulated experience to implement changes. To conclude, the positive response about implemented changes is one of the factors shaping the readiness to change in other departments. Thus, the positive attitude can be influenced by efficient communication. In addition, the behaviour of managers influence the behaviour and attitudes of the subordinates.

\section{Conclusions}

The review of scientific literature let us conclude that scholars emphasize different aspects of organisational changes and thus, provide different interpretations of the concept. While some scholars assume organisational changes as a certain process, others conclude that in current circumstances the changes are a constant state of organisation. Finally, a stream of scholars emphasises the need to interpret changes as a multifaceted phenomenon. The adopted attitudes have led to the different classification approaches towards changes.

Though scholars agree that changes are restricted by the resistance of individuals towards changes, there is a little agreement about success impacting factors. The success is defined by the contextual factors, content of changes, process of changes and individual characteristics. The observations of scientific literature let us conclude that the resistance to changes can be diminished through various means. These means include the readiness of organisation, the development of vision, efficient communication and education of individuals, collaboration and demonstration of power. To conclude, the success of changes remains a multifaceted phenomenon and thus, requires the managers to consider the size of organisation, the objectives and motives of changes and the types of changes. The development of assessment system let organisations to achieve defined objectives and to trace progress. Hence, the appropriate indicators of changes comprising both quantitative and qualitative ratios lead to the timely analysis, assessment and response. 
A case study of service providing company let us disclose the success impacting factors which coincide with the factors discussed in the scientific literature.

The future investigations have to lead to the agreement how to define the success of organisational changes, how to assess the costs of resistance to the changes, how to assess the exceed expectations of implemented changes, how to trace the success in implementation of changes.

\section{References}

Al-Haddad, S.; Kotnour, T. 2015. Integrating the organizational change literature: a model for successful change, Journal of Organizational Change Management 28(2): 234-262. https://doi.org/10.1108/JOCM-11-2013-0215

Anderson, L. D. 2010. Organization development: the process of leading organizational change. $1^{\text {st }}$ ed. California: Sage Publications.

Appelbaum, H. S.; Habashy, S.; Malo, L. J.; Shafiq, H. 2012. Back to the future: revisiting Kotter's 1996 change model, Journal of Management Development 31(8): 764-782. https://doi.org/10.1108/02621711211253231

Arnold, P. 2015. Evidence and leading indicators of change success, Strategic Direction 31(10): 1-5. https://doi.org/10.1108/SD-08-2015-0128

Brown, D. 2014. Experiential approach to organization development. $8^{\text {th }}$ ed. Essex: Pearson Education Limited.

Burke, W. W.; Lake, G. D.; Paine, W. J. 2009. Organization change. $1^{\text {st }}$ ed. San Francisco: Jossey-Bass.

Burnes, B. 2009. Managing change. $5^{\text {th }}$ ed. Essex: Pearson Education Limited.

Carnall, C. 2007. Managing change in organizations. $5^{\text {th }}$ ed. Essex: Pearson Education Limited.

Edmonds, J. 2011. Managing successful change, Industrial and Commercial Training 43(6): 349-353. https://doi.org/10.1108/00197851111160478

Gilley, A.; Gilley, W. J.; McMillan, S. H. 2009. Organizational change: motivation, communication, and leadership effectiveness, International Society for Performance Improvement 21(4): 75-94. https://doi.org/10.1002/piq.20039

Golembiewski, T. R.; Billingsley, K.; Yeager, S. 1976. Measuring change and persistence in human affairs: types of change generated by OD designs, The Journal of Applied Behavioral Science 12(2): 133-157. https://doi.org/10.1177/002188637601200201

Hamlin, B. 2016. HRD and organizational change: evidence-based practice, International Journal of HRD Practice, Policy and Research 1(1): 7-20.

Hurn, J. B. 2012. Management of change in a multinational company, Industrial and Commercial Training 44 (1): $41-46$. https://doi.org/10.1108/00197851211193417

Iljins, J.; Erina, I.; Gaile-Sarkane, E. 2014. Project based internationalization as a driving force for change management in higher education institutions in Latvia, in Procedia - Social and Behavioral Sciences, $19^{\text {th }}$ International Scientific Conference "Economics and Management 2014 (ICEM-2014)" 156: 47-52.

Imran, K. M.; Rehman, A. C.; Aslam, U.; Bilal, R. A. 2016. What's organization knowledge management strategy for successful change implementation? Journal of Organizational Change Management 29(7): 1097-1117. https://doi.org/10.1108/JOCM-07-2015-0130

Jansson, N. 2013. Organizational change as practice: a critical analysis, Journal of Organizational Change Management 26(6): $1003-1019$. https://doi.org/10.1108/JOCM-09-2012-0152

Johannsdottir, L.; Olafsson, S.; Davidsdottir, B. 2015. Leadership role and employee acceptance of change, Journal of Organizational Change Management 28(1): 72-96. https://doi.org/10.1108/JOCM-12-2013-0238

Kim, T. 2015. Diffusion of changes in organizations, Journal of Organizational Change Management 28 (1): $134-152$. https://doi.org/10.1108/JOCM-04-2014-0081

Kogetsidis, H. 2012. Critical systems thinking: a creative approach to organizational change, Journal of Transnational Management 17(3): 189-204. https://doi.org/10.1080/15475778.2012.706704

Korsakienė, R. 2006. Organizacinių pokyčių valdymas: teoriniai ir praktiniai aspektai, Verslas: teorija ir praktika 7(4): $237-242$.

Kotter, P. J. 1995. Leading Change: Why Transformation Efforts Fail, Harvard Business Review 4231 (April-May): 59-67.

Lee, S.; Ahn, H. 2008. Assessment of process improvement from organizational change, Information \& Management 45(5): 270-280. https://doi.org/10.1016/j.im.2003.12.016

Rehman, R. 2011. Effect of organizational change on employee job involvement: mediating role of communication, emotions and psychological contract, Information Management and Business Review 3(3): 178-184.

Ronnenberg, K.; Graham, E. M.; Mahmoodi, F. 2011. The important role of change management in environmental management system implementation, International Journal of Operations \& Production Management 31(6): 631-647. https://doi.org/10.1108/01443571111131971

Sikdar, A.; Payyazhi, J. 2014. A process model of managing organizational change during business process redesign, Business Process Management Journal 20(6): 971-998. https://doi.org/10.1108/BPMJ-02-2013-0020

Smith, E. M. 2002. Success rates for different types of organizational change, Performance Improvement 41(1): 26-33. https://doi.org/10.1002/pfi.4140410107

Smith, I. 2011. Organizational quality and organizational change. Interconnecting paths to effectiveness, Library Management 32(1): 111128. https://doi.org/10.1108/01435121111102629

Soparnot, R. 2011. The concept of organizational change capacity, Journal of Organizational Change Management 24(5): 640-661. https://doi.org/10.1108/09534811111158903

Walker, H. J.; Armenakis, A. A.; Bernerth, J. B. 2007. Factors influencing organizational change efforts, Journal of Organizational Change Management 20(6):761-773. https://doi.org/10.1108/09534810710831000

Witteloostuijn, van A.; Zeyse, C. J. 2013. A theoretical framework of organizational change, Journal of Organizational Change Management 26(5): 772-792. 